\title{
Como a estrutura de capital afeta o desempenho empresarial e a criação de valor: um estudo de caso de frigorífico brasileiro no período de 2008 a 2015
}

\author{
How the capital structure affects business performance and value creation: a case study of a
} Brazilian slaughterhouse from 2008 to 2015

Cómo la estructura de capital afecta el desempeño empresarial y la creación de valor: un estudio de caso de un matadero brasileño de 2008 a 2015

Recebido: 14/01/2021 | Revisado: 18/01/2021 | Aceito: 18/01/2021 | Publicado: 21/01/2021

\author{
Téucle Mannarelli Filho \\ ORCID: https://orcid.org/0000-0003-0040-0517 \\ Universidade Estadual Paulista, Brasil \\ E-mail: teucle@terra.com.br \\ Lívia Barbosa Mannarelli \\ ORCID: https://orcid.org/0000-0002-7556-5773 \\ Centro Universitário Toledo, Brasil \\ E-mail: liviabmannarelli@gmail.com
}

\begin{abstract}
Resumo
O estudo tem como objetivo verificar de que maneira a Estrutura de Capital afeta o Desempenho Empresarial e Criação de Valor em de uma empresa brasileira, do setor frigorífico e de carnes, com atuação a nível global, de capital aberto e com suas ações negociadas na Bolsa brasileira B3, por meio de Análise de Demonstrações Financeiras, no período compreendido de 2008 até 2015. A pesquisa foi realizada com base nos dados coletados na Economática, foram feitos os ajustes de deflação e posteriormente calculados os principais Índices e Indicadores Financeiros da empresa, com base em seu Balanço Patrimonial, Demonstrativo de Resultados e Fluxo de Caixa. Utilizou-se Análise Horizontal, Análise Vertical e o cálculo dos índices: Liquidez, Lucratividade, Rentabilidade, Endividamento; sendo focada para entender como a Estrutura de Capital afeta o Desempenho Empresarial e a Criação de Valor. O estudo permite concluir que a forma inadequada na estrutura de capital da empresa no período de análise, realizada com um grande endividamento em 2010 e 2011, somente garante a empresa uma boa liquidez e capacidade de pagamento de curto prazo; e não consegue agregar valor econômico, nem desempenho empresarial.
\end{abstract}

Palavras-chave: Criação de valor; Desempenho empresarial; Análise das demonstrações financeiras; Estrutura de capital.

\begin{abstract}
The study aims to verify how the Capital Structure affects the Business Performance and Value Creation of a Brazilian company, in the meat and meat sector, operating globally, publicly traded and with its shares traded on the Stock Exchange Brazilian company B3, through Analysis of Financial Statements, in the period from 2008 to 2015. The research was carried out based on the data collected in Economática, deflation adjustments were made and later the main financial indexes and indicators of the company were calculated, with based on its Balance Sheet, Income Statement and Cash Flow. Horizontal Analysis, Vertical Analysis and the calculation of the indices were used: Liquidity, Profitability, Profitability, Indebtedness; being focused to understand how the Capital Structure affects Business Performance and Value Creation. The study allows to conclude that the inadequate form in the capital structure of the company in the period of analysis, carried out with a great debt in 2010 and 2011, only guarantees the company a good liquidity and capacity of payment in the short term; and fails to add economic value or business performance.
\end{abstract}

Keywords: Value creation; Business performance; Analysis of financial statements; Capital structure.

\section{Resumen}

El estudio tiene como objetivo verificar cómo la Estructura de Capital afecta el Desempeño Comercial y la Creación de Valor de una empresa brasileña, en el sector cárnico y cárnico, operando globalmente, cotizando en bolsa y con sus acciones cotizadas en Bolsa. Empresa brasileña B3, mediante Análisis de Estados Financieros, en el período de 2008 a 2015. La investigación se realizó con base en los datos recolectados en Economática, se realizaron ajustes por deflación y posteriormente se calcularon los principales Índices e Indicadores Financieros de la empresa, con con base en su Balance General, Cuenta de Resultados y Flujo de Caja. Se utilizaron Análisis Horizontal, Análisis Vertical y el cálculo de los índices: Liquidez, Rentabilidad, Rentabilidad, Endeudamiento; centrarse en comprender 
cómo la estructura de capital afecta el rendimiento empresarial y la creación de valor. El estudio permite concluir que la forma inadecuada en la estructura de capital de la empresa en el período de análisis, realizado con un gran endeudamiento en 2010 y 2011, sólo garantiza a la empresa una buena liquidez y capacidad de pago en el corto plazo; y no agrega valor económico o desempeño comercial.

Palabras clave: Creación de valor; Rendimiento del negócio; Análisis de estados financieros; Estructura de capital.

\section{Introdução}

O presente estudo se propõe a verificar de que maneira a Estrutura de Capital afeta o Desempenho Empresarial e Criação de Valor em de uma empresa brasileira, do setor frigorífico e de carnes, com atuação a nível global, de capital aberto, no período de 2008 até 2015; utilizam-se como fonte primária de dados, suas Demonstrações Contábeis que foram devidamente publicadas e estão disponíveis na Economática, ainda que se realiza um ajuste deflacionário pela inflação para melhor comparar os dados e calcular os índices.

A elaboração das Análises Horizontais, que segundo Gitman, (1987) representam a evolução das principais contas das Demonstrações Financeiras ao longo do tempo, e poderemos verificar o comportamento da evolução dos ativos, da receita, dos custos, do lucro, das despesas financeiras entre outras contas; o que vai nos permitir entender o que ocorreu na empresa no período analisado. Ainda segundo Brigham \& Ehrhardt, (2007), é importante o cálculo da estrutura das demonstrações financeiras, e fazemos isso com o cálculo de quocientes entre as diferentes contas, verificando assim sua evolução no tempo.

O cálculo dos denominados Índices Financeiros vai permitir um melhor entendimento dos principais aspectos gerencias e operacionais da empresa, e segundo Brigham e Ehrhardt (2007), podemos agrupar estes índices como: Liquidez, Lucratividade, Rentabilidade, Endividamento e Desempenho Empresarial com criação de valor. Utilizaremos cálculos em planilhas Excel e complementarmente criam-se alguns gráficos para melhor demonstrar e visualizar todos os aspectos da empresa estudada no período de análise de 2008 a 2015.

Finalmente procura-se responder à questão básica, se a maneira como a empresa frigorifica estrutura seu capital no período de análise, afeta o Desempenho Empresarial e Criação de Valor no período analisado, e quais são os fatores que contribuíram para se criar valor e, na hipótese de não criação de valor, o que aconteceu para a empresa não cumprisse seu objetivo empresarial e complementarmente o pode ser feito para corrigir os eventuais problemas encontrados.

\section{Metodologia}

Trata-se de uma pesquisa exploratória, em um estudo de caso único, que foi escolhido por conveniência e aderência ao tema que se busca investigar, realizada a campo por meio de entrevistas e que metodologicamente, todas as etapas e procedimentos são melhor detalhados na sequência e seguem os procedimentos metodológicos de (Pereira, Shitsuka, Parreira, \& Shitsuka, 2018)

A pesquisa apresentada neste artigo constitui-se em um estudo de caso único de natureza exploratória, qualitativa, quantitativa e descritiva; utilizando-se simultaneamente de métodos qualitativos e quantitativos para o seu desenvolvimento; e nos aspectos relativos a sua caracterisitca de caso único, segue as recomendaçoes de (Yin, 2015).

Realiza-se um levantamento de dados primários das Demonstrações Financeiras: Balanço Patrimonial, Demonstração de Resultados e Fluxo de Caixa; da empresa frigorifica, que atua no setor de carnes, abate de bovinos, e outros segmentos empresarias de proteínas animais, possui suas ações comercializadas na Bolsa brasileira B3. As Demonstrações Financeiras, foram coletadas da consultoria Economatica e deflacionadas pela inflação no período de 2008 a 2015 e anualizadas.

A seguir utilizando a ferramenta Microsoft ${ }^{\circledR}$ Excel (MS-Excel), realizou-se o cálculo dos principais indicadores contábeis, em dois tipos básicos de análise: Horizontal e Vertical; sendo a Horizontal para medir a evolução das contas das Demonstrações Financeiras e também de alguns índices ao longo do tempo pesquisado. Ainda se realizou uma Análise 
Vertical, com objetivo de criar indicadores e quocientes entre diferentes contas, e verificar a variação relativa e também a evolução ao longo do tempo.

O estudo de caso, que vai permitir amplos e detalhadas análises sobre os principais indicadores da empresa, sendo que se agruparam os principais índices calculados por afinidade: Liquidez, Lucratividade, Rentabilidade, Endividamento e finalmente Resultado Econômico, Geração de Valor.

Realizou-se uma abordagem quantitativa para identificar a questão básica a que esta pesquisa objetiva, qual seja: Como entender o Desempenho Empresarial e a criação de valor da empresa do setor frigorifico, se existe criação de valor econômico, como se dá, e na outra vertente se existe problemas, quais são eles e onde a empresa esta com problemas ou com decisões equivocadas.

Complementarmente criaram-se quadros, que nos permitem melhor compreender a evolução não só das contas dos Demonstrativos, mas principalmente dos principais indicadores que vão ser calculados; deste modo realizando um exaustivo estudo analítico que nos permite ampliar os conhecimentos sobre a empresa e ao mesmo tempo detalhando os resultados que vão sendo obtidos. A interpretação dos resultados vai ser baseada em informações teóricas, pesquisadas na literatura e na revisão bibliográfica realizada; sendo que realizaremos algumas recomendações de gestão e ações gerenciais baseadas nos resultados que foram encontrados.

\section{Revisão Bibliográfica}

Estrutura de capital é um assunto que vem sendo intensamente discutido pelos pesquisadores da área financeira, especialmente a partir do trabalho de (Modigliani \& Miller, 1958). A questão principal que envolve o tema é se a forma como a empresa é financiada influencia ou não o seu valor. Podem ser identificadas duas grandes correntes teóricas sobre estrutura de capital: a tradicionalista (teoria convencional), representada principalmente por Durand, (1952), e a proposta por (Modigliani \& Miller, 1958).

A teoria tradicional defende que a estrutura de capital influencia o valor da empresa, em que o custo do capital de terceiros mantém-se estável até um determinado nível de endividamento, a partir do qual se eleva devido ao aumento do risco de falência. Como o custo de capital de terceiros é inferior ao custo do capital próprio, a empresa deveria se endividar até o ponto em que o seu custo de capital total tingisse um patamar mínimo. Esse ponto representaria a estrutura de capital ótima, que levaria à maximização do valor da empresa. Em contraposição à teoria convencional e baseada em um conjunto de pressupostos bastante restritivos, Modigliani e Miller, (1958) argumentaram que a forma com que a empresa é financiada é irrelevante para o seu valor. Para os autores, o custo de capital da empresa é o mesmo para qualquer nível de endividamento e, portanto, não haveria uma estrutura de capital ótima.

Dessa forma, o valor de uma empresa não é função da forma como ela é financiada, mas sim dos fluxos de caixa por ela gerados e do seu risco. A partir dessa discussão, diversas pesquisas passaram a ser realizadas com o objetivo de identificar os fatores que explicam a forma com que as empresas se financiam, dando origem à teoria moderna de estrutura de capital. Muitos trabalhos avaliaram a questão considerando as imperfeições existentes no mercado, como impostos, custos de falência, custos de agência e assimetria de informações, entretanto, o crescimento das dívidas pressiona os fluxos de caixa da empresa em razão da obrigação com pagamento de juros e amortização do principal, levando a uma maior probabilidade de falência e, consequentemente, à elevação do custo de capital de terceiros. Assim, a partir de certo nível de endividamento, o benefício fiscal decorrente da utilização das dívidas é anulado pelo aumento do risco de falência (Scott, 1976), (De Angelo \& Masulis, 1980).

De forma simplificada, uma empresa pode financiar suas novas oportunidades de investimento por meio de capital próprio ou capital de terceiros. A opção por financiar o investimento por meio de dívidas sinaliza ao mercado que a 
administração acredita que as ações da empresa estão subavaliadas. Essa decisão representa um sinal positivo ao mercado, pois a riqueza produzida pelo novo investimento será absorvida apenas pelos atuais acionistas. Segundo essa teoria, para evitar uma sinalização negativa ao mercado e reduzir o seu valor, as empresas mantêm uma reserva de capacidade de endividamento para utilização em futuros investimentos.

A partir das pesquisas sobre assimetria informacional, Myers, (1984) propôs a Teoria do "Pecking Order", que considera a existência de uma hierarquia nas fontes de financiamento, ou seja, assume-se que as empresas priorizam o uso de uma fonte de recursos em relação à outra. Para essa teoria, as empresas em geral preferem financiar seus investimentos por meio de recursos internos (retenção de lucros). Caso esses recursos não sejam suficientes, a segunda opção é o financiamento por meio de dívidas e, por fim, se ainda houver a necessidade de recursos, são emitidas novas ações. Segundo Brito, Corrar, \& Batistella, (2007) as teorias sobre estrutura de capital foram construídas, ao contrário das economias desenvolvidas, o mercado brasileiro apresenta certas ineficiências que impactam, diretamente, nas decisões de financiamento das empresas. Entre essas imperfeições, destacam-se o mercado de capitais restrito, a elevada concentração do controle acionário das empresas e a forte restrição de fontes de capital de terceiros de longo prazo. Adicionalmente, as elevadas taxas de juros tornam os custos de financiamento bastante significativos, fazendo com que as empresas no Brasil apresentem baixos níveis de endividamento.

Outra característica do mercado brasileiro, segundo Brito, Corrar, e Batistella, (2007) é o fato de o custo de capital de terceiros não ser função apenas do risco do tomador, mas também da natureza da fonte de financiamento; em razões disso, determinadas linhas de crédito de longo prazo direcionadas a investimentos específicos têm custo financeiro inferior a linhas de curto prazo, cujo risco de crédito para o credor normalmente é menor. Esses aspectos tornam ainda mais difíceis o estudo das formas de financiamento das empresas no Brasil. Segundo Albanez e Valle, (2009) a Teoria do Trade Off, foca em uma dívida alvo, como objetivo para a empresa estruturar seu capital, ou seja, um valor alvo de recursos de terceiros que vai ser atingido, que pode melhor explicar a estrutura de capital em mercados mais maduros e Países desenvolvidos, mas com pouca validação no mercado brasileiro pelas suas características.

Um ponto importante nesta literatura é a determinação do "Relationship Banking", ou seja, de que maneira o relacionamento bancário pode ser complementar aos outros tipos de financiamento, em especial, o financiamento junto a mercados descentralizados de capital. Neste caso, Hoshi, Kashyap e Scharfstein, (1993) mostra que o financiamento bancário expõe o empreendedor ao monitoramento do intermediário, o que facilitaria a obtenção de recursos junto ao mercado de capitais. Neste caso, as duas formas de financiamento - direto e intermediado; seriam complementares e contemporâneos.

Diamond, (1991), por outro lado, apresenta um modelo em que os dois tipos de financiamento não são complementares, mas sequenciais. A obtenção de credito bancário, intensivo na obtenção de informação especifica ao consumidor, estabelece uma reputação que permite que, após um determinado número de ciclos de financiamento, o empreendedor possa utilizar os serviços de financiamento junto ao mercado de capitais.

Já no trabalho de Halov, (2019), é proposto um modelo de decisões financeiras em um ambiente com informação assimétrica dinâmica (a assimetria muda com o passar do tempo), em que a escolha por títulos depende não só do custo de seleção adversa atual do título, mas, também, do ambiente de informação futuro e das necessidades futuras de financiamento da empresa. $\mathrm{O}$ autor identifica um novo custo da dívida que surge nessa colocação dinâmica. Enquanto, em um modelo de um único período, a dívida sempre e preferida a ações porquê e menos sensível a informação privada de administradores, com múltiplos projetos de investimento sobrepostos, a dívida emitida hoje torna emissões futuras de títulos mais sensíveis ao grau de informação assimétrica no período de emissão. A análise é realizada em empresas norte-americanas no período 1986-2005, e o resultado principal e que a emissão de dívida e relacionada positivamente com a informação assimétrica do período atual e relacionada negativamente com a informação assimétrica e necessidades futuras de investimento. 
Estudos de Agarwal e O'hara, (2007) fazem uma distinção entre assimetria de informação intrínseca e extrínseca e verificam os impactos desta última na estrutura de capital das empresas. Segundo os autores, na literatura de estrutura de capital, a assimetria é vista como intrínseca. A empresa, ou seja, ocorre porque administradores são mais bem informados que investidores externos, o que a acaba levando a pecking order, na qual empresas com grande assimetria informacional primeiro emitem títulos menos sensíveis a informação e depois se movem para os mais vulneráveis a ela. Assim, em empresas em que os administradores possuem uma grande vantagem informacional, os índices de alavancagem são altos. Já a assimetria de informação extrínseca e aquela entre grupos de investidores externos.

Para Klein, O’Brien, e Peters, (2002) o potencial da assimetria de informação em contribuir para o entendimento das decisões financeiras das empresas e suas escolhas de estrutura de capital é evidente, ressaltando que, dentre os muitos resultados empíricos que surgiram ao longo dos estudos realizados, alguns se destacam, como o de que o preço da ação da empresa cai, em média, em resposta a um anúncio de emissão de ações, e que um aumento ou diminuição na alavancagem resulta em um aumento ou diminuição do preço acionário, sugerindo que os administradores transmitam informações ao mercado por meio de suas decisões financeiras. No entanto, os autores afirmam que não há um suporte empírico definitivo para explicar as decisões financeiras das empresas, sugerindo que as teorias nem sempre são corroboradas pelos testes empíricos. Assim sendo, é possível esperar resultados contrários e a favor da teoria de pecking order.

Segundo Frydenberg, (2004) e Leary e Roberts, (2002), não encontram forte apoio para a referida teoria; já os trabalhos de Shyam-sunder e Myers, (1999) e Fama e French, (2002), corroboram suas predições. De acordo com Frank \& Goyal, (2003), um problema particularmente importante presente na teoria de pecking order e a utilização da emissão de ações como forma de financiamento, afirmando que as empresas emitem muito mais ações, e em momentos errados, do que prevê a teoria. Ainda Frydenberg, (2004) afirma que a percepção do mercado de capitais do que constitui uma estrutura de capital normal pode castigar empresas que tem uma estrutura de capital que diverge daquela e, mesmo que a empresa se beneficie de uma alavancagem mais alta, a percepção de credores e investidores de uma estrutura de capital normal pode forçar a redução da alavancagem.

Segundo Tarantin Junior e Valle, (2015) no caso brasileiro, o BNDES (Banco Nacional de Desenvolvimento Econômico e Social) é tido como um ofertante de capital responsável pela oferta de capitais de longo prazo na economia do país. Uma característica marcante desses recursos é o fato de terem taxas de juros subsidiadas.

Ainda Giambiagi, Leal, Moreira, e Favaret, (2009) ao longo de várias décadas, o BNDES foi praticamente a única instância nacional que forneceu recursos de longo prazo para o financiamento da indústria e da infraestrutura. Lazzarini, Musacchio, Bandeira de Melo, e Marcon, (2011) relatam que, em 2010, os empréstimos do BNDES representaram 21\% do total de crédito ao setor privado e grande parte do crédito de longo prazo.

Cabe destacar uma questão que relaciona os empréstimos subsidiados ao mercado de capitais, sendo que Lazzarini, Musacchio, Bandeira de melo, e Marcon, (2011) argumentam que se não existir uma evidência sistemática ao nível micro, não se tem como identificar se os empréstimos dos bancos de desenvolvimento atingem seus objetivos, bem com quais são os critérios utilizados na identificação dos tomadores destes empréstimos.

A questão, segundo Tarantin Junior e Valle, (2015); os empréstimos subsidiados podem criar distorções no mercado de crédito à medida que cobram taxas abaixo das praticadas pelo mercado. Em um contexto como esse, o desenvolvimento do mercado de capitais brasileiro pode ficar prejudicado, e segundo Lazzarini, Musacchio, Bandeira de melo, \& Marcon, (2011) não existem informações para mensurar outros impactos positivos que tais empréstimos e investimentos podem estar gerando distorções no mercado de credito. 


\section{Resultados e Discussão}

\subsection{Análise horizontal}

Inicialmente os dados das Demonstrações Financeiras se apresentam das principais contas e indicadores do Balanço Patrimonial, Demonstrativo de Resultados. O Quadro 1 abaixo apresenta a evolução das principais contas do Ativo da empresa, com a finalidade de compreender sua evolução temporal.

Quadro 1 - Evolução das principais contas do Ativo no período de 2008 a 2015 (R\$).

\begin{tabular}{|l|r|r|r|r|r|r|r|r|}
\hline ATIVO & \multicolumn{1}{c|}{2008} & \multicolumn{1}{c|}{2009} & \multicolumn{1}{c|}{2010} & \multicolumn{1}{c|}{2011} & \multicolumn{1}{c|}{2012} & \multicolumn{1}{c|}{2013} & \multicolumn{1}{c|}{2014} & 2015 \\
\hline Ativo Total & 14.847 .909 & 17.804 .596 & 33.176 .589 & 32.837 .754 & 33.326 .217 & 21.921 .823 & 23.327 .073 & 21.839 .661 \\
\hline Ativo Circ. & 7.088 .012 & 10.158 .425 & 13.799 .716 & 12.900 .414 & 13.329 .016 & 9.214 .732 & 9.670 .757 & 10.277 .128 \\
\hline $\begin{array}{l}\text { Ativo N } \\
\text { Circ. }\end{array}$ & 7.759 .897 & 7.646 .171 & 19.376 .873 & 19.937 .340 & 19.997 .201 & 12.707 .091 & 13.656 .316 & 11.562 .533 \\
\hline Investime & 0 & 0 & 14.739 & 18.188 & 14.465 & 67.353 & 42.681 & 27.173 \\
\hline Ativo L.P & 625.008 & 964.505 & 2.993 .976 & 3.833 .402 & 4.247 .132 & 3.196 .548 & 4.243 .389 & 4.209 .160 \\
\hline
\end{tabular}

Fonte: Autores.

Podemos observar a evolução das principais contas do Ativo e também alguns quocientes que são relevantes para fazermos a análise; o Ativo tem uma evolução crescente desde 2008, até atingir um pico em 2012 e posteriormente começa a declinar. As contas do Ativo Circulante se mantêm relativamente constantes, o que indica que o aumento do Ativo Total se da pelo aumento dos Ativos Não Circulantes; complementarmente observa-se um aumento crescimento significativo dos Investimentos até atingir um pico em 2013, com posterior redução ate 2015 e com tendência de queda.

É importante analisarmos as principais relações entre as contas do Ativo a partir de 2010, sendo que não se observam alterações significativas ao longo do tempo, ou seja, Ativo Circulante / Ativo Total, Ativo Não Circulante / Ativo Total e o Ativo Imobilizado / Ativo Total, vão se manter relativamente constantes ao longo do tempo nas suas relações. O Quadro 2 permite uma visualização temporal das contas do Passivo e do Patrimônio Liquido, no período de análise.

Quadro 2 - Evolução das principais contas do Passivo no período de 2008 a 2015 (R\$).

\begin{tabular}{|c|c|c|c|c|c|c|c|c|}
\hline PASSIVO & 2008 & 2009 & 2010 & 2011 & 2012 & 2013 & 2014 & 2015 \\
\hline Passivo Total & 14.847 .909 & 17.804 .596 & 33.176 .589 & 32.837 .754 & 33.326 .217 & 21.921 .823 & 23.327 .073 & 21.839 .661 \\
\hline Passivo Circulante & 4.540 .233 & 4.628 .502 & 10.200 .607 & 9.198 .066 & 10.011 .519 & 4.535 .678 & 5.387 .999 & 5.645 .423 \\
\hline $\begin{array}{l}\text { Passivo Não } \\
\text { Circulante }\end{array}$ & 5.851 .330 & 6.649 .494 & 17.091 .080 & 18.926 .712 & 17.707 .997 & 13.550 .812 & 15.544 .964 & 15.313 .349 \\
\hline $\begin{array}{l}\text { Exigível Longo } \\
\text { Prazo } \\
\end{array}$ & 4.997.394 & 5.722 .365 & 9.696 .897 & 12.629 .844 & 11.442 .984 & 9.738 .429 & 10.944 .627 & 10.584 .064 \\
\hline Patrimônio Líquido & 4.456 .345 & 6.526 .600 & 5.884 .902 & 4.712 .976 & 5.606 .702 & 3.835 .333 & 2.394 .110 & 880.889 \\
\hline
\end{tabular}

Fonte: Autores.

O Passivo Total tem uma evolução crescente até atingir em 2010, um patamar muito elevado, mantendo-se constante em 2011 e 2012, sendo que começa a decair para um novo patamar e com tendência de estabilizar-se. O Passivo Circulante acompanha a evolução do aumento do Passivo Total; entretanto o que nos chama atenção é a evolução do Passivo Não Circulante, que aumenta em 2010, mas permanece em níveis elevados, indicando um aumento do endividamento da empresa.

O Exigível de Longo Prazo vai comprovar este aumento do endividamento em 2010, que permanece a partir daí elevado e constante; indicando também que o aumento do endividamento se dá por dívidas de longo prazo.

O Patrimônio Líquido manteve-se relativamente constante até 2012 e partir daí começa a diminuir de modo constante e preocupante, até atingir em 2015 valores muito baixos, indicando um sério problema para a empresa, que vem perdendo seu 
Patrimônio Líquido; que provavelmente está sendo corroído por resultados negativos. O Quadro 3 apresenta a evolução do rateio entre as principais contas do Balanço Patrimonial da empresa no período de análise.

Quadro 3 - Evolução do rateio das contas do Balanço no período de 2008 a 2015.

\begin{tabular}{|l|l|l|l|l|l|l|l|r|}
\hline PASSIVO & 2008 & 2009 & 2010 & 2011 & 2012 & 2013 & 2014 & 2015 \\
\hline P.Circ /P. Total & $30,58 \%$ & $26,00 \%$ & $30,75 \%$ & $28,01 \%$ & $30,04 \%$ & $20,69 \%$ & $23,10 \%$ & $25,85 \%$ \\
\hline P.N Circ /P.Total & $39,41 \%$ & $37,35 \%$ & $51,52 \%$ & $57,64 \%$ & $53,14 \%$ & $61,81 \%$ & $66,64 \%$ & $70,12 \%$ \\
\hline Exig. LP / P.Total & $33,66 \%$ & $32,14 \%$ & $29,23 \%$ & $38,46 \%$ & $34,34 \%$ & $44,42 \%$ & $46,92 \%$ & $48,46 \%$ \\
\hline Patr. Liq / P.T & $30,01 \%$ & $36,66 \%$ & $17,74 \%$ & $14,35 \%$ & $16,82 \%$ & $17,50 \%$ & $10,26 \%$ & $4,03 \%$ \\
\hline
\end{tabular}

Fonte: Autores.

A análise dos quocientes, o que nos chama atenção é a redução do Patrimônio Líquido em relação ao Passivo Total atingindo apenas 4,03\% em 2015, e aumento relativo do Exigível de Longo Prazo em relação ao Passivo Total, indicando aumento do endividamento de longo prazo. O aumento constante ao longo do tempo do Passivo Não Circulante, também mostra alguma distorção pelo aumento significativo das atividades não circulantes.

A visão geral das contas do Passivo indica como já dissemos um problema significativo de aumento do endividamento de Longo Prazo, e uma redução preocupante do Patrimônio Líquido.

O Quadro 4 abaixo apresenta a evolução das principais contas do Demonstrativo de Resultados da empresa nos anos em que se realiza a analise, sendo valores em reais deflacionados.

Quadro 4 - Evolução das contas do DRE no período de 2008 a 2015 (R\$).

\begin{tabular}{|l|r|r|r|r|r|r|r|r|}
\hline \multicolumn{1}{|c|}{$\begin{array}{c}\text { DEM. RES. } \\
\text { DRE }\end{array}$} & \multicolumn{1}{c|}{2008} & 2009 & 2010 & 2011 & 2012 & 2013 & 2014 & 2015 \\
\hline Receita Líquida & 10.061 .352 & 14.950 .204 & 23.309 .871 & 30.165 .721 & 30.899 .876 & 23.059 .027 & 24.352 .579 & 19.726 .154 \\
\hline CMV & 7.909 .262 & 12.802 .462 & 19.490 .904 & 25.834 .000 & 26.264 .633 & 20.218 .915 & 21.272 .677 & 17.322 .319 \\
\hline Lucro Bruto & 2.152 .091 & 2.147 .741 & 3.818 .967 & 4.331 .720 & 4.635 .243 & 2.840 .111 & 3.079 .902 & 2.403 .835 \\
\hline Desp. Operacionais & 0 & 0 & 2.533 .362 & 2.908 .852 & 3.122 .409 & 1.774 .299 & 1.826 .695 & 1.069 .278 \\
\hline Resultado Financeiro & -1.558 .652 & 300.268 & -1.684 .171 & -3.182 .577 & -2.710 .687 & -2.497 .430 & -2.457 .714 & -3.222 .898 \\
\hline Desp. Financeiras & 2.715 .412 & 1.100 .134 & 2.471 .468 & 4.511 .088 & 3.807 .476 & 3.903 .196 & 3.700 .930 & 5.946 .605 \\
\hline Lucro EBIT & 1.175 .138 & 847.471 & 1.285 .605 & 1.422 .869 & 1.512 .834 & 1.065 .812 & 1.253 .207 & 1.334 .556 \\
\hline LAIR & -383.515 & 883.865 & -398.567 & -1.759 .709 & -1.197 .852 & -1.431 .618 & -1.204 .507 & -1.888 .342 \\
\hline Imposto de Renda & -343.513 & 79.525 & -604.224 & -730.496 & -560.287 & -444.313 & -372.128 & -712.630 \\
\hline Lucro Líquido & -57.574 & 1.055 .807 & 214.469 & -1.028 .288 & -291.597 & -1.123 .408 & -854.543 & -611.903 \\
\hline
\end{tabular}

Fonte: Autores.

A evolução das principais contas do Demonstrativo de Resultados está apresentada no Quadro acima, sendo que podemos verificar que a Receita Líquida tem um aumento significativo ate 2011 e 2012 e a partir daí começa a declinar, o Custo da Mercadoria Vendida tende a acompanhar esta variação observada nas Receitas.

O que chama atenção é a evolução do Resultado Financeiro que aumenta em 2011, acompanhando as Receitas, indicando que houve um aumento significativo no endividamento; entretanto o resultado financeiro não diminui como as Receitas, o que indica que a empresa manteve seu nível de endividamento mesmo com a redução das Receitas nos anos 2013 , 2015 e 2015.

O Lucro EBIT (Earn Before Interest and Taxs) vai manter-se constante ao longo do tempo, mostrando que mesmo com o aumento das vendas, ou seja, um crescimento das atividades operacionais da empresa, o Lucro Operacional, medido pelo Lucro EBIT não aumentou; e a manutenção de margens operacionais e um crescimento de despesas não operacionais, notadamente as financeiras. O Lucro antes do imposto de renda, medido pelo LAIR (Lucro Antes do Imposto de Renda), e 
também o lucro líquido apresentam-se negativos, e de maneira constante, ressalvado o ano de 2009 e 2010; anos précrescimento das Receitas e antes do aumento do endividamento da empresa; isto acarreta sérios problemas para a empresa, pois ela não consegue reter os lucros que são gerados, e o Imposto de renda negativo mostra apenas benefícios fiscais de aproveitamento tributário, mas que só servem para reverter parte dos resultados negativos finais da empresa. O Quadro 5 apresenta uma evolução horizontal e temporal do período de análise, das Margens da empresa, que são calculadas por meio de uma divisão dos diferentes níveis de resultado pela receita total.

Quadro 5 - Evolução das margens obtidas no DRE no período de 2008 a 2015 (R\$).

\begin{tabular}{|l|l|l|l|l|l|l|l|l|}
\hline DEM. RES. DRE & \multicolumn{1}{|c|}{2008} & 2009 & 2010 & 2011 & 2012 & \multicolumn{1}{l}{2013} & \multicolumn{1}{l}{2014} & 2015 \\
\hline Margem Bruta & $21,39 \%$ & $14,37 \%$ & $16,38 \%$ & $14,36 \%$ & $15,00 \%$ & $12,32 \%$ & $12,65 \%$ & $12,19 \%$ \\
\hline $\begin{array}{l}\text { Margem } \\
\text { Operacional }\end{array}$ & $11,68 \%$ & $5,67 \%$ & $5,52 \%$ & $4,72 \%$ & $4,90 \%$ & $4,62 \%$ & $5,15 \%$ & $6,77 \%$ \\
\hline Margem Líquida & $-0,57 \%$ & $7,06 \%$ & $0,92 \%$ & $-3,41 \%$ & $-0,94 \%$ & $-4,87 \%$ & $-3,51 \%$ & $-3,10 \%$ \\
\hline
\end{tabular}

Fonte: Autores.

A Margem Bruta, desde 2008 vem tendo uma Redução significativa e persistente, indicando problemas com os custos dos produtos vendidos, e que mesmo nos anos de aumento das vendas 2011 e 2012 a Margem Bruta mantém a mesma tendência de queda; ou seja, a empresa enfrenta problemas com seus custos, que de algum modo vem subindo e comprometendo a Margem Bruta.

A Margem Operacional tem uma redução grande de 2008 para 2009, mas a partir daí mantem-se relativamente constante na faixa de 5\%, que é muito baixa; com um leve aumento em 2015, pouco significativa.

A Margem Líquida que sai de um patamar positivo em 2009 e 2010 fica persistente negativa até 2015; indicando sérios problemas para a empresa, que não retém os lucros que são gerados, e como podemos constatar não são problemas operacionais, mas na forma como estruturou seu capital e seu nível de endividamento de longo prazo, ou seja, ao que parece as despesas financeiras, estão comprometendo o lucro liquido da empresa, com uma transferência de margens para o setor financeiro. A evolução das Margens mostra a Redução da Margem Bruta, indicando problemas com o Custo das Mercadorias Vendidas, e a Margem Líquida que além de negativa após 2011 também tem tendência a aumentar.

\subsection{Análise vertical}

A análise vertical que representa um melhor entendimento conceitual da relação entre as diferentes contas das Demonstrações Financeiras da empresa: Balanço Patrimonial e Demonstrativo de Resultados; serão apresentados neste estudo, ano a ano e ainda em sua evolução temporal no período de 2008 a 2015, com a finalidade de melhor compreender esta evolução ao longo do tempo.

\subsection{1 Índices de liquidez}

A liquidez pode ser mensurada por diversos índices, que correlacionam as várias contas do Balanço e do Demonstrativo de Resultados, e tem como objetivo primordial, analisar a capacidade de pagamento da empresa.

O Quadro 6 apresenta a evolução dos Índices de Liquidez, que medem a capacidade de pagamento de curto prazo da empresa. 
Quadro 6 - Evolução dos índices de liquidez no período de 2008 a 2015.

\begin{tabular}{|l|c|c|c|c|c|c|c|c|}
\hline $\begin{array}{l}\text { INDICES DE } \\
\text { LIQUIDEZ }\end{array}$ & 2008 & 2009 & 2010 & 2011 & 2012 & 2013 & 2014 & 2015 \\
\hline Liquidez Geral & 1,56 & 2,19 & 1,35 & 1,40 & 1,33 & 2,03 & 1,79 & 1,82 \\
\hline Liquidez Seca & 1,00 & 1,61 & 1,03 & 1,02 & 0,98 & 1,54 & 1,36 & 1,54 \\
\hline Liquidez Imediata & - & - & 0,56 & 0,52 & 0,41 & 0,49 & 0,57 & 0,93 \\
\hline
\end{tabular}

Fonte: Autores.

Os Índices de Liquidez da empresa, medidos, como Geral, Seco, sem os estoques, e Imediato, como os recursos disponíveis em caixa; são bastante robustos e mostram uma boa capacidade de pagamento de curto prazo da empresa, pois mesmo o Índice de Liquidez seco, apresenta-se no período acima de 1; indicando boa capacidade de pagamento e podemos ressaltar que em 2015 a Liquidez Imediata atinge quase 1, mostrando que com os recursos financeiros em caixa e aplicados são suficientes para pagamento de todo passivo circulante, demonstrando ótima liquidez.

Os prazos médios de estoque, recebimento e ainda o ciclo operacional da empresa, são apresentados no Quadro 7 abaixo.

Quadro 7 - Evolução dos prazos médios de estoque, recebimento e ciclo operacional.

\begin{tabular}{|l|r|r|r|r|r|r|r|r|}
\hline LIQUIDEZ-PRAZOS & 2008 & 2009 & 2010 & 2011 & 2012 & 2013 & 2014 & 2015 \\
\hline Prazo Médio Estoque & 117 & 75 & 61 & 49 & 48 & 40 & 40 & 32 \\
\hline Prazo Médio Recebimento & 0 & 0 & 31 & 21 & 27 & 37 & 28 & 19 \\
\hline Ciclo Operacional & 117 & 75 & 92 & 70 & 75 & 77 & 67 & 52 \\
\hline
\end{tabular}

Fonte: Autores.

O Quadro 7 apresenta uma evolução positiva para a empresa na redução do Prazo Médio de Estoque, e uma redução significativa no Ciclo Operacional empresa. O Prazo Médio de Recebimento apresenta-se em zero em 2008 e 2009 , indicando vendas a vista, e que segue a partir de 2010 em valores entre 19 e 37 dias, indicando boa liquidez nas vendas.

O Quadro 8 apresenta os demais índices de liquidez da empresa, no período de 2008 a 2015, com destaque especial para o Saldo em Tesouraria.

Quadro 8 - Evolução dos demais índices de liquidez no período de 2008 a 2015.

\begin{tabular}{|l|r|r|r|r|r|r|r|r|}
\hline LIQUIDEZ & 2008 & 2009 & 2010 & 2011 & 2012 & 2013 & 2014 & 2015 \\
\hline COMPRAS & & 15.068 .886 & 23.927 .632 & 30.346 .616 & 30.938 .132 & 21.786 .339 & 24.447 .571 & 18.945 .741 \\
\hline $\begin{array}{l}\text { Prazo Médio } \\
\text { Pagamentos }\end{array}$ & & 31 & 51 & 46 & 39 & 32 & 35 & 36 \\
\hline $\begin{array}{l}\text { Ciclo } \\
\text { Financeiro }\end{array}$ & & 106 & 143 & 115 & 115 & 110 & 102 & 88 \\
\hline $\begin{array}{l}\text { Ativo Circ } \\
\text { Financ. }\end{array}$ & 0 & 0 & 5.690 .559 & 4.792 .572 & 4.139 .095 & 2.227 .571 & 3.072 .537 & 5.225 .211 \\
\hline $\begin{array}{l}\text { Ativo Circ } \\
\text { Operac. }\end{array}$ & 7.088 .012 & 10.158 .425 & 8.109 .157 & 8.107 .842 & 9.189 .921 & 6.987 .161 & 6.598 .220 & 5.051 .917 \\
\hline & & & & & & & \\
\hline $\begin{array}{l}\text { Passivo Circ. } \\
\text { Financ. }\end{array}$ & 1.998 .222 & 2.291 .117 & 4.512 .068 & 3.469 .720 & 4.873 .077 & 1.442 .273 & 1.999 .264 & 2.137 .803 \\
\hline $\begin{array}{l}\text { Passivo Circ. } \\
\text { Operac. }\end{array}$ & 2.542 .012 & 2.337 .385 & 5.688 .539 & 5.728 .346 & 5.138 .442 & 3.093 .405 & 3.388 .736 & 3.507 .620 \\
\hline $\begin{array}{l}\text { Saldo } \\
\text { Tesouraria }\end{array}$ & 1.998 .222 & -2.291 .117 & 1.178 .491 & 1.322 .852 & -733.982 & 785.298 & 1.073 .273 & 3.087 .408 \\
\hline
\end{tabular}

Fonte: Autores. 
O Prazo Médio de Pagamento de Fornecedores tem uma relativa estabilidade ao longo do tempo, e o Ciclo Financeiro tem uma redução em 2015, mas que se da em função da redução do Prazo Médio de Recebimento de Fornecedores.

As contas do Ativo Circulante Financeiro e Operacional são estáveis ao longo período, com uma redução pontual no ano de 2013 e as variações no Ativo Circulante Operacional estão consistentes com o aumento ocorrido nas Receitas nos de 2010, 2011e 2012. Os Passivos Circulantes e Operacionais estão também com relativa estabilidade, e consistentes com o nível de atividades e suas variações temporais.

O Saldo de Tesouraria, que representa os Ativos Circulantes Financeiros - Passivos Circulantes Financeiros (ACF PCF), é negativo em 2008 e 2009, e a partir 2010 até 2015 são positivos, exceto em 2012, e que em 2015 obtém seu maior valor; indicando que em 2010, 2011 a empresa fez importante captação de recursos financeiros que vão impactar seu Saldo de Tesouraria. A Necessidade de Capital de Giro, que mede as necessidades operacionais de caixa da empresa, são altas em 2008 e 2009, posteriormente vão se reduzindo, com exceção em 2012; mostrando uma necessidade de capital de giro nestes anos anteriores a 2010, quando a empresa fez endividamento.

Alguns índices de liquidez, conseguem captar aspectos importantes da empresa, e mensurar fatores relevantes do gerenciamento da empresa; entre estes índices o Quadro 9, apresenta a evolução temporal de 2008 a 2015 , dos seguintes: necessidade de capital de giro, capital circulante liquido, coeficiente de tesoura, e o equilíbrio financeiro.

Quadro 9 - Evolução de índices de liquidez.

\begin{tabular}{|c|c|c|c|c|c|c|c|c|}
\hline LIQUIDEZ & 2008 & 2009 & 2010 & 2011 & 2012 & 2013 & 2014 & 2015 \\
\hline Necess. Capital Giro & .546 .000 & 7.821 .040 & 2.420 .619 & 2.379 .496 & 4.051 .479 & 3.893 .756 & 3.209 .484 & 1.544 .296 \\
\hline Capital Circ, Liq. CCL & 2.547 .779 & 5.529 .923 & 3.599 .109 & 3.702 .348 & 3.317 .497 & 4.679 .054 & 4.282 .757 & 4.631 .705 \\
\hline Coeficiente Tesoura & 0,20 & 0,15 & 0, & 0,04 & 0,02 & 0,03 & 0,04 & 0,16 \\
\hline Equilíbrio Financeiro & 0,25 & 0,37 & 0,15 & 0,12 & 0,11 & 0,20 & 0,18 & 0,23 \\
\hline
\end{tabular}

Fonte: Autores.

O Capital Circulante Líquido, que vai medir o saldo entre Ativo Circulante-Passivo Circulante (AC-PC), apresenta-se relativamente estável, com exceção para aos aportes financeiros que são feitos pela empresa, em 2009 e posteriormente em patamares mais altos em 2013, 2014, 2015; com indicação que a empresa está com mais recursos em caixa, como já pudemos indicar anteriormente.

O Coeficiente Tesoura, que vai correlacionar o Saldo de Tesouraria com as Receitas Líquidas, e deve ser positivo e sempre crescente; não acontece com a empresa, indicando decisões erráticas na gestão financeira, principalmente na forma faz seu endividamento e como estrutura seu capital. Finalmente o Equilíbrio Financeiro apresenta uma estabilidade somente rompida nos anos 2010 a 2012 pelo aumento das Receitas, mas apresenta-se consistente com uma gestão de manter caixa na empresa.

\subsubsection{Lucratividade}

A análise da Lucratividade é medida como a capacidade da empresa em reter a renda gerada em suas atividades, e neste sentido se faz necessário realizar alguns ajustes para corrigir os efeitos: tributário, financeiro e da depreciação; o cálculo do NOPAT (Net Operacional Profit After Taxes), que representa o lucro líquido após os impostos e o EBITDA (Earn Before Interest, Taxs and Depreciation) ajudado pelos efeitos das receitas financeiras; vai nos dar uma melhor dimensão da Lucratividade da empresa.

O Quadro 10 apresenta os principais indicadores financeiros para mensuração da Lucratividade da empresa. 
Quadro 10 - Evolução de índices de liquidez.

\begin{tabular}{|l|c|c|c|c|c|r|r|r|}
\hline LUCRATIVIDADE & \multicolumn{1}{c|}{2008} & \multicolumn{1}{c|}{2009} & \multicolumn{1}{c|}{2010} & \multicolumn{1}{c|}{2011} & \multicolumn{1}{c|}{2012} & \multicolumn{1}{c|}{2013} & \multicolumn{1}{l}{2014} & 2015 \\
\hline Margem Bruta & $21,39 \%$ & $14,37 \%$ & $16,38 \%$ & $14,36 \%$ & $15,00 \%$ & $12,32 \%$ & $12,65 \%$ & $12,19 \%$ \\
\hline $\begin{array}{l}\text { Ebit Ajustado=Ebit+Rec } \\
\text { Fin }\end{array}$ & 2.331 .897 & 2.247 .873 & 2.072 .901 & 2.751 .379 & 2.609 .624 & 2.471 .578 & 2.496 .423 & 4.058 .263 \\
\hline $\begin{array}{l}\text { Aliquota IR/Csocial= } \\
\text { IR/LAIR }\end{array}$ & $90 \%$ & $9 \%$ & $152 \%$ & $42 \%$ & $47 \%$ & $31 \%$ & $31 \%$ & $38 \%$ \\
\hline Imp Renda & 2.088 .673 & 202.250 & 3.142 .503 & 1.142 .161 & 1.220 .633 & 767.071 & 771.260 & 1.531 .523 \\
\hline NOPAT & 243.224 & 2.045 .623 & 1.069 .602 & 1.609 .218 & 1.388 .991 & 1.704 .506 & 1.725 .163 & 2.526 .740 \\
\hline MARGEM NOPAT & $2,4 \%$ & $13,7 \%$ & $-4,6 \%$ & $5,3 \%$ & $4,5 \%$ & $7,4 \%$ & $7,1 \%$ & $12,8 \%$ \\
\hline
\end{tabular}

Fonte: Autores.

A Margem Bruta, anteriormente identificada nas Análises Horizontais, estão em queda consistentes, indicando um sério problema para a empresa em sua capacidade de reter renda, e problemas com o aumento nos Custos das Mercadorias Vendidas. O EBIT (Earnings Before Interest and Taxes) ajustado com as receitas financeiras tem um aumento significativo em 2015.

O NOPAT (Net Operating Profit After Taxes) apresenta-se negativo no ano de 2010 e um aumento no ano de 2015 , basicamente pelos efeitos tributários ajustados, já que a empresa não consegue lucratividade em suas atividades e ainda os ajustes tributários não mostram um padrão adequado.

\subsubsection{Rentabilidade}

Os indicadores utilizados dizem respeito à capacidade da empresa na geração de renda com suas atividades operacionais; e o conceito de Investimento ao invés de Ativos Totais, sendo o investimento, como a somatória dos financiamentos de Curto e Longo prazo acrescidos do Patrimônio Liquido, para melhor entender os aspectos relevantes da Rentabilidade.

Os principais indicadores de Rentabilidade se apresentam no Quadro 11, com destaque para a ROA (Return on Assets) e o ROE (Return on Investiment).

Quadro 11 - Evolução dos índices de Rentabilidade.

\begin{tabular}{|l|r|r|r|r|r|r|r|r|}
\hline RENTABILIDADE & 2008 & 2009 & 2010 & 2011 & 2012 & 2013 & 2014 & 2015 \\
\hline INVESTIMENTO & 11.451 .962 & 14.540 .082 & 20.093 .868 & 20.812 .540 & 21.922 .762 & 15.016 .035 & 15.338 .000 & 13.602 .756 \\
\hline GIRO DO ATIVO & 0,88 & 1,03 & 1,16 & 1,45 & 1,41 & 1,54 & 1,59 & 1,45 \\
\hline ROI = NOPAT/INVE & $2,12 \%$ & $14,07 \%$ & $-5,32 \%$ & $7,73 \%$ & $6,34 \%$ & $11,35 \%$ & $11,25 \%$ & $18,58 \%$ \\
\hline Margem NopadxGiro & $2,12 \%$ & $14,07 \%$ & $-5,32 \%$ & $7,73 \%$ & $6,34 \%$ & $11,35 \%$ & $11,25 \%$ & $18,58 \%$ \\
\hline ROA= NOPAT/AT & $1,64 \%$ & $11,49 \%$ & $-3,22 \%$ & $4,90 \%$ & $4,17 \%$ & $7,78 \%$ & $7,40 \%$ & $11,57 \%$ \\
\hline ROE & $-1,29 \%$ & $16,18 \%$ & $3,64 \%$ & $-21,82 \%$ & $-5,20 \%$ & $-29,29 \%$ & $-35,69 \%$ & $-69,46 \%$ \\
\hline
\end{tabular}

Fonte: Autores.

Os Investimentos que foram calculados mostram um aumento nos anos de 2010 a 2012, explicados pelo aumento das Receitas neste período, voltando aos patamares normais de investimento de 2008 e 2009, o aumento do Investimento nos anos de 2010, 2011 e 2012 não se dá por aquisições, incorporações ou novas plantas industriais, mas por endividamento de longo prazo. O Giro de Ativos tem um aumento consistente no período e bastante relevante, ficando em patamares elevados a partir de 2011.

O ROI (Return on Investiment), medido pela relação do lucro Nopad / Investimento, mostra um comportamento com volatilidade e sem padrão definido de 2008 ate 2012 e a partir de 2013 apresenta aumento consistente ate atingir em 2015 um 
valor elevado e como já pudemos observar anteriormente, este fato não parece estar ligado com suas atividades operacionais, mas sim com a elevada quantidade de caixa disponível na empresa.

O ROA (Return on Assets) apresenta variações ao longo do tempo, mas em 2015 atinge valores aceitáveis e importantes ressaltar que somente em 2010 a empresa teve ROA negativo. O ROE, como medida relevante do retorno do Capital Próprio e a visualização da rentabilidade do acionista; apresenta-se muito preocupante, pois os valores após 2011 são negativos e crescentes, atingindo patamares catastróficos em 2015, isto deve explicado pelos Lucros Líquidos que são negativos e contribuem para a redução do Patrimônio Liquido que vem acontecendo.

Finalmente com a constatação que de o ROE é menor que o ROI, tem a indicação que a empresa esta com problemas na sua Estrutura de Capital, confirmado por outros indicadores já discutidos.

\subsubsection{Endividamento}

Preliminarmente devem-se fazer algumas considerações sobre as duas principais teorias financeiras sobre a forma com que as empresas tomam suas decisões financeiras de endividamento, ou seja, utilização de recursos de terceiros nas suas atividades.

A Teoria denominada Trade Off, segundo (Albanez \& Valle, 2009), está associada a mercados mais maduros, em países desenvolvidos; e preconiza que a empresa busca uma meta de endividamento, em função de um chamado nível de endividamento ótimo; ou seja, que a empresa tem um endividamento alvo ou meta. A Teoria de Percking Off, inicialmente proposta por Myers, (1984), por outro lado hierarquiza a decisão de endividamento nas empresas, preconizando que prioritariamente as empresas vão buscar recursos próprios, que são gerados internamente, basicamente lucros acumulados, posteriormente buscam recursos de terceiro e finalmente procuram capitalização de recursos próprios dos sócios e novos sócios; deste modo esta teoria não tem endividamento alvo e explicam melhor os mercados menos maduros e em países em desenvolvimento.

O Quadro 12 apresenta os principais índices de endividamento da empresa, que corresponde a utilização de recursos de terceiros nas atividades da empresa.

Quadro 12 - Evolução de índices de endividamento de 2008 a 2015.

\begin{tabular}{|c|c|c|c|c|c|c|c|c|}
\hline ENDIVIDAMENTO & 2008 & 2009 & 2010 & 2011 & 2012 & 2013 & 2014 & 2015 \\
\hline kd nominal & $38,82 \%$ & $13,73 \%$ & $17,39 \%$ & $28,02 \%$ & $23,34 \%$ & $34,91 \%$ & $28,59 \%$ & $46,74 \%$ \\
\hline Benefício fiscal & 2.432 .186 & 98.983 & 3.746 .727 & 1.872 .657 & 1.780 .920 & 1.211 .384 & 1.143 .388 & 2.244 .153 \\
\hline IR & -343.513 & 103.266 & -604.224 & -730.496 & -560.287 & -444.313 & -372.128 & -712.630 \\
\hline Despesa financeira real & 283.226 & \begin{tabular}{|l}
1.001 .151 \\
\end{tabular} & -1.275 .259 & 2.638 .431 & 2.026 .556 & 2.691 .812 & 2.557 .542 & 3.702 .452 \\
\hline Kd real & $4,05 \%$ & $12,49 \%$ & $-8,98 \%$ & $16,39 \%$ & $12,42 \%$ & $24,08 \%$ & $19,76 \%$ & $29,10 \%$ \\
\hline EBITDA Ajust +Depr-amort & 2.591 .010 & 2.674 .587 & 2.992 .943 & 3.773 .486 & 3.671 .200 & 3.093 .009 & 3.170 .897 & 4.510 .254 \\
\hline Razão de pgto & 1,7 & 1,7 & 1,7 & 1,7 & 1,7 & 1,7 & 1,7 & 1,7 \\
\hline Pgto "ideal" & 1.524 .123 & 1.573 .286 & 1.760 .555 & 2.219 .698 & 2.159 .529 & 1.819 .417 & 1.865 .234 & 2.653 .091 \\
\hline Pgto Amort + juros & 259.113 & 426.714 & 920.042 & 1.022 .107 & 1.061 .577 & 621.432 & 674.474 & 451.991 \\
\hline $\begin{array}{l}\text { prazo médio financiamento } \\
\text { em anos }\end{array}$ & 7 & 7 & 7 & 7 & 7 & 7 & 7 & 7 \\
\hline divida alvo $=$ Valor presente & 9.131 .456 & \begin{tabular}{|l}
7.069 .158 \\
\end{tabular} & 18.270 .821 & 8.862 .824 & 9.725 .497 & 5.887 .751 & 6.768 .134 & 7.591 .235 \\
\hline $\begin{array}{l}\text { passivo oneroso = Divida } \\
\mathrm{CP}+\mathrm{LP}\end{array}$ & 6.995 .616 & 8.013 .482 & 14.208 .965 & 16.099 .564 & 16.316 .061 & 11.180 .702 & 12.943 .891 & 12.721 .866 \\
\hline Financiamento=ebitda/1,7 & 1.524 .123 & & & & & & & \\
\hline
\end{tabular}

Fonte: Autores.

O EBITDA (Earn Before Interest Tax Depreciation Amortization) ajustado pela depreciação está relativamente constante, indicando que a empresa vem mantendo seus resultados operacionais, e quando se calcula o pagamento ideal de 
dívidas pela relação padrão utilizada pelo mercado de 1,7; consta-se que o pagamento ideal de amortizações, despesas financeiras mantem-se relativamente também constante, para um prazo médio estimado de financiamento de 7 anos.

Deste modo considerando a Teoria Trade Off, para uma dívida alvo calculada, temos valores relativamente constantes e somente no ano 2010 tivemos um valor muito elevando, indicando que a empresa poderia ter se endividado ainda mais. Ainda que estes valores da dívida alvo, são calculados pelo valor presente pelo Kd real. Ainda quando se compara o Passivo Oneroso, composto pelas dívidas de Curto e Longo Prazo da empresa, com a Dívida Alvo, constata-se o Passivo Oneroso real da empresa a partir de 2010 esta sempre acima da Dívida Alvo, indicando problemas na forma como a empresa esta se endividando e estruturando seu capital.

Complementarmente o Quadro 13, apresenta outros índices de endividamento da empresa, que ajudam a compreender a dinâmica da estrutura de capital da empresa.

Quadro 13 - Evolução de demais índices de endividamento de 2008 a 2015.

\begin{tabular}{|l|c|c|c|c|c|c|c|c|}
\hline ENDIVIDAMENTO & 2008 & 2009 & 2010 & 2011 & 2012 & 2013 & 2014 & 2015 \\
\hline Participação do endividamento & $61,09 \%$ & $55,11 \%$ & $70,71 \%$ & $77,36 \%$ & $74,43 \%$ & $74,46 \%$ & $84,39 \%$ & $93,52 \%$ \\
\hline Participação do CP & $28,56 \%$ & $28,59 \%$ & $31,76 \%$ & $21,55 \%$ & $29,87 \%$ & $12,90 \%$ & $15,45 \%$ & $16,80 \%$ \\
\hline Spread = roi/kd real & $-1,92 \%$ & $1,58 \%$ & $3,65 \%$ & $-8,66 \%$ & $-6,08 \%$ & $12,72 \%$ & $-8,51 \%$ & $-10,53 \%$ \\
\hline Nível de alavancagem= PO/PL & 1,57 & 1,23 & 2,41 & 3,42 & 2,91 & 2,92 & 5,41 & 14,44 \\
\hline
\end{tabular}

Fonte: Autores.

A participação do Endividamento da empresa tem um aumento consistente ao longo do período analisado, sendo que atinge em 2015 valores muito elevados, quando se verifica a participação do Endividamento de Curto Prazo, constata-se que a empresa ao mesmo tempo em que aumenta seu endividamento, faz um alongamento nos prazos de pagamento, aumentando o prazo médio de seu endividamento.

O spread do custo da dívida real em relação ao ROI apresenta-se negativo e crescente, somente nos anos de 2009 e 2010 estão positivos, o que indica que a partir de 2011 o custo real da divida medido pelo Kd real esta sempre maior que seus retornos sobre investimento, comprometendo o desempenho da empresa e indicando um endividamento inadequado pelo pagamento de taxas financeiras acima dos retornos conseguidos pela empresa em seus investimentos.

O nível de alavancagem tem aumento significativo em 2014 e 2015, mas esta alavancagem se dá por um maior endividamento, que ao invés de melhorar o lucro da empresa, só faz piorar, pois a empresa faz dívidas com taxas financeiras maiores que seu ROI, deste modo quanto maior sua alavancagem maior serão seus problemas.

\subsubsection{Resultado econômico e geração de valor}

Para construção da análise do Resultado Econômico e geração de valor da empresa, deve-se que inicialmente calcular o CAPM (Capital Asset Price Model), ou seja, determinar o custo do capital dos acionistas; e constata-se um CAPM relativamente estável e que somente em 2015 tem um aumento e sempre acima da taxa livre de risco Selic e considerando um beta da empresa de 0,45 e um prêmio de risco do mercado de $9 \%$.

O Quadro 14 apresenta os principais índices de geração de valor, em especial o CAPM (Capital Asset Pricing Model) e o Beta da empresa e a comparação com o prêmio de risco e Selic e cabe ressaltar que os valores da Selic e do Prêmio de Risco, estimou-se em valores que se apresentavam durante o período de análise; sendo estes valores atualmente são diferentes. 
Quadro 14 - Evolução do CAPM, Beta em relação Prêmio Risco e Selic.

\begin{tabular}{|l|c|c|r|r|r|r|r|r|}
\hline GERAÇÃO VALOR & 2008 & 2009 & 2010 & 2011 & 2012 & 2013 & 2014 & 2015 \\
\hline CAPM= custo patr. líquido & $17,72 \%$ & $12,70 \%$ & $14,72 \%$ & $14,96 \%$ & $11,31 \%$ & $13,95 \%$ & $15,70 \%$ & $18,20 \%$ \\
\hline Beta & 0,45 & 0,45 & 0,45 & 0,45 & 0,45 & 0,45 & 0,45 & 0,45 \\
\hline Prêmio & $9 \%$ & $9 \%$ & $9 \%$ & $9 \%$ & $9 \%$ & $9 \%$ & $9 \%$ & $9 \%$ \\
\hline Selic & $13,67 \%$ & $8,65 \%$ & $10,67 \%$ & $10,91 \%$ & $7,26 \%$ & $9,90 \%$ & $11,65 \%$ & $14,15 \%$ \\
\hline
\end{tabular}

Fonte: Autores.

Uma vez determinado o Custo do Capital Próprio calculado pelo CAPM, calcula-se qual seria a remuneração esperada pelos acionistas; sendo o Resultado Econômico medido pelo Lucro Líquido efetivo menos a remuneração que seria esperada pelos acionistas.

O Quadro 15 apresenta o Resultado Econômico da empresa e ainda o pagamento aos acionistas e o lucro líquido da empresa.

Quadro 15 - Evolução de demais índices de resultado econômico de 2008 a 2015.

\begin{tabular}{|l|r|r|r|r|r|r|r|r|}
\hline GERAÇÃO VALOR & 2008 & 2009 & 2010 & 2011 & 2012 & 2013 & 2014 & 2015 \\
\hline Pg ao acionista=PLxCAPM & 789.664 & 828.878 & 866.258 & 705.061 & 634.118 & 535.029 & 375.875 & 160.322 \\
\hline & & & & - & - & - & & - \\
lucro líquido & -57.574 & 1.055 .807 & 214.469 & 1.028 .288 & 291.597 & 1.123 .408 & -854.543 & 611.903 \\
\hline & - & & - & - & - & - & - & - \\
Resultado Econômico & 847.239 & 226.929 & 651.789 & 1.733 .349 & 925.715 & 1.658 .437 & 1.230 .418 & 772.224 \\
\hline
\end{tabular}

Fonte: Autores.

A empresa somente em 2009 conseguiu ter Resultado Econômico positivo, ou seja, conseguiu remunerar o capital dos acionistas, nos demais anos, sistematicamente a empresa não consegue remunerar o capital dos acionistas; e não tem resultado, nem para remunerar os acionistas e muito menos para gerar valor para a empresa com um Desempenho muito ruim e preocupante.

A Geração de Valor de uma empresa pode ainda ser mensurada por alguns indicadores importantes, tais como: RROI (Rapid Return on Investment), EVA (Economic Value Added), MVA (Market Value Added) e o próprio Valor da empresa (Ativo total + MVA) e ainda o WACC (Weighted Average Cost of Capital), que representa o custo médio ponderado de capital; estes indicadores estão descritos no Quadro 16.

Quadro 16 - Evolução dos índices de agregação de valor econômico da empresa.

\begin{tabular}{|l|r|r|r|r|r|r|r|r|}
\hline \multicolumn{1}{|c|}{$\begin{array}{c}\text { GERAÇÃO } \\
\text { VALOR }\end{array}$} & 2008 & 2009 & 2010 & 2011 & 2012 & 2013 & 2014 & 2015 \\
\hline $\begin{array}{l}\text { WACC CUSTO DA } \\
\text { DÍVIDA }\end{array}$ & $9,37 \%$ & $12,59 \%$ & $-2,04 \%$ & $16,06 \%$ & $12,14 \%$ & $21,49 \%$ & $19,13 \%$ & $28,40 \%$ \\
\hline RROI & $-7,24 \%$ & $1,48 \%$ & $-3,29 \%$ & $-8,33 \%$ & $-5,80 \%$ & $-10,14 \%$ & $-7,88 \%$ & $-9,82 \%$ \\
\hline & & & & & & & & \\
\hline $\begin{array}{l}\text { EVA= VALOR ECON } \\
\text { ADICIONADO }\end{array}$ & -829.666 & 215.594 & -660.600 & -1.734 .274 & -1.271 .683 & -1.522 .334 & -1.208 .254 & -1.336 .034 \\
\hline MVA & 8.855 .801 & 1.712 .958 & 32.454 .671 & 10.795 .495 & 10.478 .102 & -7.084 .151 & -6.317 .617 & -4.704 .843 \\
\hline $\begin{array}{l}\text { Valor empresa } \\
\text { (AT+MVA) }\end{array}$ & 5.992 .108 & 19.517 .553 & 65.631 .260 & 22.042 .259 & 22.848 .116 & 14.837 .672 & 17.009 .456 & 17.134 .818 \\
\hline
\end{tabular}

Fonte: Autores. 
O cálculo do EVA (Economic Value Added) que vai correlacionar o Investimento com o RROI (Rate of Return on Investiment) é importante para verificar qual é o Valor Econômico que a empresa esta adicionado em suas atividades; ainda o MVA (Market Value Added) que correlaciona o WACC (Weighted Average Capital Cost) com o EVA, inferindo se o nível de endividamento e o custo da dívida estão adicionado valor a empresa; e finalmente o Valor da Empresa medido como a soma dos Ativos Totais com o MVA.

A análise do WACC mostra um custo da dívida crescente a partir de 2011 até atingir em 2015 28,40\% muito superior seu ROI (Return on Investiment), e somente em 2010, quando foi feito importante aporte de recursos via endividamento o WACC foi negativo; ainda que o RROI se mostre de maneira constante negativo, indicando problemas na relação do ROI com o WACC, trazendo o custo da dívida para níveis acima da capacidade de geração de retornos sobre seus investimentos, ou seja, um endividamento inadequado.

A geração de valor econômico adicionado medido pelo EVA indica valores negativos, ou seja, a empresa não consegue gerar valor e pelo contrário perde valor ao longo do tempo; ainda que o valor adicionado de mercado medido pelo MVA, apresenta-se positivo de 2008 ate 2012, mas a partir de 2013 também se torna negativo, indicando perda de valor de mercado após 2013. Finalmente que o valor da empresa, tem um aumento significativo em 2010, pelo endividamento feito, mas que após 2011 ocorre uma redução e mantem-se relativamente estável.

\section{Conclusões}

Pode-se concluir a empresa possui uma boa liquidez e capacidade de pagamento de curto prazo, que foi conseguida por um endividamento feito de maneira inadequada em 2010 e 2011, mantendo apenas o dinheiro em caixa e aplicações financeiras. Este endividamento ainda foi feito com taxas superiores ao ROI da empresa, comprometendo ao longo do tempo o Lucro Líquido da empresa.

A deterioração do Patrimônio Líquido se dá de uma maneira muito rápida e preocupante, além da ROE ser negativo e menor que o ROI, indicando sérios problemas de gestão da empresa no que diz respeito à preservação e criação de valor para seus acionistas.

As Margens também apresentam problemas, em especial a Margem Bruta, indicando um aumento do CMV e perda da eficiência operacional, complementarmente o endividamento inadequado, feito ao que parece apenas para manter dinheiro em caixa, reflete em uma Margem Líquida Negativa e persistente.

A análise do EVA, MVA e VALOR DA EMPRESA, também confirmam os problemas enfrentados pela empresa com seu endividamento inadequado, mostrando que a empresa apresenta um EVA negativo, indicando perda de valor ao longo do tempo, sendo que o Valor da Empresa e o MVA, somente aumentam em 2010, quando foi feito o endividamento, para posteriormente começarem a cair de modo significativo, embora o Valor da Empresa se estabilize a partir de 2013, provavelmente pela manutenção de alta liquidez com dinheiro em aplicações financeiras e em caixa.

Ainda com base nos resultados, pode-se sugerir ações gerenciais para correção dos problemas constatados; em duas frentes principais. Primeiro tentar edificar quais são os fatores que afetam as operações empresariais, e que está fazendo o Custo das Mercadorias Vendidas aumentar e buscar recuperar a Margem Bruta; paralelamente uma segunda linha de atuação vai ao sentido de reestruturar o endividamento da empresa de longo prazo, com renegociação de taxas, ou buscando novas fontes de financiamento com taxas que possam ser menores que o Custo de Capital real da empresa; a empresa dispõe de caixa e aplicações financeiras que podem reforçar esta estratégia de renegociação pela sua boa liquidez imediata e de curto prazo. Estas ações gerenciais em um curto espaço de tempo, de até um ano podem surtir efeitos positivos nos problemas acima edificados e reverter à situação preocupante em que a empresa se encontra. Ainda que a empresa com a alta disponibilidade de 
recursos financeiros pode prospectar novas aquisições ao longo de sua cadeia de produção ou até mesmo diversificar seus investimentos.

Finalmente o estudo tem como restrição, ser um caso único e deste modo não pode ser aplicado em outras empresas, e que os dados foram coletados em bases disponíveis e de livre acesso, sem qualquer entrevista com a empresa para melhor compreender as razoes deste posicionamento empresarial.

A partir deste trabalho novas linhas de pesquisa emergem, no sentido de melhor compreender este importante assunto, no âmbito de estudar outras empresas, do mesmo setor ou não; em estudos multicasos, para ter uma melhor dimensão de como a estruturação de capital impacta na criação de valor nas empresas.

\section{Referências}

Agarwal, P., \& O’hara, M. (20 de outubro de 2007). Information risk and capital structure. http://papers.ssrn.com/.

Albanez, T., \& Valle, M. R. (Set/Dez de 2009). Impactos da assimetria de informação na estrutura de capital de empresas brasileiras abertas. Revista Contabilidade e Finanças da USP.

Brigham, E., \& Ehrhardt, M. (2007). Administração Financeira. Thomson.

Brito, G. A., Corrar, L. J., \& Batistella, F. D. (2007). Fatores determinantes da estrutura de capital das maiores empresas que atuam no Brasil. Revista Contabilidade \& Finanças, 18(43), 9-19., pp. 9-19.

De Angelo, H., \& Masulis, R. W. (1980). Optimal capital structure under corporate and personal taxation. Journal of Financial Economics.

Diamond, D. W. (1991). Monitoring and reputation: The choice between bank loans and directly placed debt. Journal of Political Economy, pp. 689-721.

Durand, D. (1952). Cost of debt and equity funds for business: trends and problems of measurement. Conference on Research on Business Finance. New York: Nacional Bureau of Economic Research.

Fama, E. F., \& French, K. R. (2002). Testing trade-off and pecking order predictions about dividends and debt. Review of Financial Studies, pp. 1-33.

Frank, M. Z., \& Goyal, V. K. (feb. de 2003). Testing the pecking order theory of capital structure. Journal of Financial Economics, $217-248$.

Frydenberg, S. (2004). Theory of capital structure: a review. http://papers.ssrn.com/.

Giambiagi, F., Leal, G. B., Moreira, M. M., \& Favaret, F. (2009). O financiamento de longo prazo e o futuro do BNDES. Em F. Giambiagi, G. B. Leal, M. M. Moreira, \& F. Favaret, Brasil pós-crise: agenda para a próxima década (pp. 267-287). Rio de Janeiro: Elsevier.

Gitman, L. (1987). Princípios de Administração Financeira. São Paulo: Harbra.

Halov, N. (16 de out. de 2019). Dynamics of asymmetric information and capital structure. Fonte: SSRN Working Paper: http://papers.ssrn.com/ .

Hoshi, T., Kashyap, A., \& Scharfstein, D. (1993). The choice between public and private debt: An analysis of post-deregulation corporate financing in Japan. Tokio: NBER Working Papers 4421, National Bureau Of Economic Research, Inc.

Klein, L. S., O’Brien, T. J., \& Peters, S. R. (2002). Debt vs. equity and asymmetric information: a review. The Financial Review, $317-349$.

Lazzarini, S. G., Musacchio, A., Bandeira de melo, R., \& Marcon, R. (2011). What do development banks do? Evidence from Brazil, 2002-2009. Harvard Business School.

Leary, M. T., \& Roberts, M. R. (2002). The pecking order, debt capacity, and information asymmetry. Fonte: SSRN Working Paper: http://papers.ssrn.com.

Modigliani, F., \& Miller, M. H. (1958). The cost of capital, corporation finance and the theory of investment. The American Economic Review, pp. 261-297.

MYERS, S. (jul. de 1984). The capital structure puzzle. Journal of Finance Chicago: American Finance Association.

Myers, S. C. (1984). The capital structure puzzle. Journal of Finance. Chicago: American Finance Association.

Pereira, A. S., Shitsuka, D. M., Parreira, F. J., \& Shitsuka, R. (2018). Metodologia da Pesquisa Científica. Santa Maria: Universidade de Santa Maria.

Scott, J. A. (1976). Theory of optimal capital structure. The Bell Journal of Economics.

Shyam-sunder, L., \& Myers, S. C. (feb. de 1999). Testing static tradeoff against pecking order models of capital structure. Journal of Financial Economics, pp. of capital structure. Journal of Financial Economics, 51(2),219-244.

Tarantin junior, W., \& Valle, M. R. (set./out./nov./dez. de 2015). Estrutura de Capital: o papel das fontes de financiamento nas quais companhias abertas se baseiam. Revista Contabilidade Finanças da USP, São Paulo, 26(69), 331-344.

Yin, R. K. (2015). Estudo de caso: planejamento e métodos. Bookman. 